\title{
Hubungan Pemberian Makanan Tambahan Dini terhadap Status Gizi Bayi Usia 4-6 Bulan di Daerah Pantai Kota Padang Tahun 2013
}

\author{
Fenny Oktrina Fauthrisna ${ }^{1}$, Masrul $^{2}$, Eva Chundrayetti ${ }^{3}$
}

\begin{abstract}
Abstrak
Indonesia merupakan salah satu negara dengan angka kematian bayi dan balita tertinggi di dunia, dengan persentase gizi kurang dalam kriteria sedang dan berat. Hal ini berkaitan dengan beberapa faktor, salah satunya adalah pemberian makanan tambahan dini. Makanan tambahan dini adalah makanan selain ASI yang diberikan pada bayi sebelum usia 6 bulan. Pemberian makanan tambahan dini tersebut dapat menyebabkan gangguan-gangguan kesehatan, seperti diare, infeksi saluran pernafasan, dan lain-lain, yang akan memengaruhi status gizi bayi. Tujuan penelitian ini adalah untuk mengetahui hubungan pemberian makanan tambahan dini terhadap status gizi bayi usia 46 bulan. Metode penelitian menggunakan pendekatan cross sectional, dengan populasi adalah seluruh ibu yang mempunyai bayi usia 4-6 bulan di kecamatan Padang Barat, Padang Utara, dan Koto Tangah, kota Padang dan jumlah sampel sebanyak 126 orang. Data diambil melalui pengukuran antropometri (penimbangan berat badan dan usia bayi) dan kuisioner. Hubungan antar variabel dianalisis menggunakan Fisher's Exact Test. Hasil uji statistik menunjukkan nilai $p$ 0,043 ( $p$ value $<0,05$ ), yang berarti terdapat hubungan yang bermakna antara pemberian makanan tambahan dini dengan status gizi bayi usia 4-6 bulan. Kesimpulan penelitian ini ialah pemberian makanan tambahan dini dapat menyebabkan gizi kurang pada bayi usia 4-6 bulan.
\end{abstract}

Kata kunci: makanan tambahan dini, status gizi, bayi, gizi kurang

\begin{abstract}
Indonesia is one of countries which has highest infant and child mortality in the world, with the percentage of malnutrition in moderate and severe criteria. It is related to several factors, one of which is an early complementary feeding. Early complementary food is the food other than breast milk given to infants before 6 months of age. Early supplementary feeding can cause health problems, such as diarrhea, respiratory tract infections, etc., which will affect the nutritional status of infants. The objective of this study was to determine the relationship of early complementary feeding on the nutritional status of infants aged 4-6 months. This research is using a cross sectional study' method, however the entire population is mothers with infants aged 4-6 months in the district of West Padang, North Padang and Koto Tangah, Padang city and the total sample of 126 people. Data retrieved through anthropometric measurements (weight and age of babies) and questionnaires. Relationships between variables were analyzed using Fisher's Exact Test. Statistical test results showed the $p$ value of 0.043 ( $p$ value $<0.05$ ), which means that there is a significant relationship between early complementary feeding and nutritional status of infants aged 4-6 months. The conclusion is early supplementary feeding can cause malnutrition in infants aged 4-6 months.
\end{abstract}

Keywords: early complementary feeding, nutritional status, infant, malnutrition

Affiliasi penulis: 1. Pendidikan Dokter FK UNAND (Fakultas Kedokteran Universitas Andalas Padang), 2. Bagian Gizi FK UNAND, 3. Bagian IImu Kesehatan Anak FK UNAND,
Korespondensi: Fenny Oktrina Fauthrisna,E-mail: fny1710_fauthrisna@yahoo.com, Telp: 085263115882 


\section{PENDAHULUAN}

Gizi memegang peranan penting dalam setiap siklus kehidupan, bahkan sejak dalam kandungan (janin). Periode dua tahun pertama kehidupan bayi merupakan masa-masa kritis karena pada saat itu terjadi pertumbuhan dan perkembangan yang pesat. Dari segi gizi, pada masa itu anak harus mendapatkan asupan gizi yang cukup agar tercapai tumbuh kembang yang optimal. ${ }^{1}$

Status gizi merupakan gambaran kesehatan sebagai refleksi dari konsumsi pangan dan penggunaannya oleh tubuh. Pemantauan dan penilaian status gizi dapat dilakukan dengan berbagai cara, salah satunya adalah dengan antropometri menggunakan baku WHO-NCHS (World Health Organization-National Center for Health Statistics) dan dihitung berdasarkan skor simpangan baku (Z-Score). ${ }^{2}$

Di Indonesia masih ditemui beberapa masalah gizi yang harus ditanggulangi dengan program perbaikan gizi. Hal ini didukung oleh data terbaru yang merupakan hasil dari Riskesdas (Riset Kesehatan Dasar) tahun 2010, prevalensi status gizi bayi usia 0-5 bulan (BB/U) menurut karakteristik responden di berbagai Provinsi di Indonesia adalah gizi buruk sebanyak $4,2 \%$, gizi kurang sebanyak $7,2 \%$, gizi normal sebanyak $82,3 \%$, dan gizi lebih sebanyak $6,2 \% .^{3}$

Prevalensi status gizi bayi berdasarkan BB/ $U$ di Provinsi Sumatera Barat mencakup gizi buruk sebanyak 2,8\%, gizi kurang sebanyak $14,4 \%$, gizi normal sebanyak $81,3 \%$, dan gizi lebih sebanyak $1,6 \%^{3}$. Prevalensi gizi kurang di beberapa daerah di kota Padang masih cukup tinggi, seperti pada daerah Padang Barat (10\%), Padang Utara $(27,48 \%)$ dan Koto Tangah $(37,36 \%){ }^{4}$

Untuk mencapai status gizi yang baik, seorang bayi memerlukan asupan nutrisi yang adekuat. The American Academy of Pediatrics merekomendasikan Air Susu Ibu(ASI) eksklusif selama 6 bulan pertama dan selanjutnya minimal selama 1 tahun. ${ }^{5}$ Selain itu, World Health Organization (WHO) dan The United Nations Children's Fund (UNICEF) juga merekomendasikan pemberian ASI eksklusif (tanpa tambahan apapun, bahkan air putih) dari sejak lahir sampai usia 6 bulan dan bayi harus selalu disusui tanpa dibatasi waktu. ${ }^{6}$
Pada kenyataannya, tidak banyak ibu-ibu yang memberikan ASI eksklusif selama 6 bulan. Hasil Rikesdas tahun 2010 (dengan mengelompokkan pola menyusui menjadi 3 kategori, yakni kategori menyusui eksklusif, menyusui predominan dan menyusui parsial) menunjukkan bahwa persentase pola menyusui pada bayi umur 0 bulan adalah 39,8\% menyusui eksklusif, $5,1 \%$ menyusui predominan, dan $55,1 \%$ menyusui secara parsial. Persentase menyusui eksklusif pun makin menurun seiring dengan pertambahan usia bayi. Pada bayi umur 5 bulan menyusui eksklusif hanya $15,3 \%$, menyusui predominan sebanyak $1,5 \%$, dan menyusui parsial sebanyak $83,2 \%{ }^{3}$

Data WHO terbaru pun memperlihatkan bahwa persentase pemberian ASI eksklusif pada bayi usia 06 bulan di beberapa negara di dunia masih tergolong rendah, termasuk Indonesia. Pada tahun 1997, persentase menyusui eksklusif di Indonesia mencapai angka 42,5\%. Namun pada tahun 2003, angka tersebut menurun menjadi 39,5\%. Data terbaru tahun 2008 menunjukkan bahwa persentase pemberian ASI eksklusif kembali turun menjadi $32,4 \%{ }^{7}$

Pemberian makanan tambahan dini pada bayi usia di bawah 6 bulan dapat memengaruhi status gizi seorang bayi. Dari hasil penelitian Murninigsih dan Sulastri di Sragen pada tahun 2007 didapatkan bahwa pemberian makanan tambahan dini sebelum bayi genap berusia 6 bulan dapat mengakibatkan tingkat kesehatan bayi tersebut menurun dan terjadinya gangguan-gangguan kesehatan lainnya di kemudian hari. Selain diare, panas, pilek, ditemui juga obesitas, Infeksi Saluran Pernapasan Atas (ISPA) dan dermatitis menyebabkan tingkat kunjungan ke pelayanan kesehatan menjadi lebih sering. ${ }^{8}$

Pemberian makanan tambahan yang terlalu dini merupakan kebiasaan yang buruk dan berbahaya. Penambahan makanan tambahan lain selain ASI dapat meningkatkan kejadian diare dan memperburuk status gizi bayi. Hal ini berkaitan dengan cara penyiapan makanan yang kurang higienis. Bakteri patogen yang ada dalam makanan yang telah terkontaminasi tersebut akan masuk ke dalam saluran cerna bayi yang masih imatur. ${ }^{9}$

Penelitian ini dilakukan dengan tujuan untuk mengetahui hubungan pemberian makanan tambahan 
dini terhadap status gizi pada bayi usia 4-6 bulan di daerah pantai kota Padang tahun 2013.

\section{METODE}

Penelitian ini menggunakan desain cross sectional. Populasi yang diambil adalah para ibu dan bayi yang berusia 4-6 bulan di 3 kecamatan di kota Padang, yaitu kecamatan Padang Barat, Padang Utara, dan Koto Tangah.

Sampel berjumlah 126 orang yang diambil dengan menggunakan teknik Total Sampling, yakni dengan cara mengambil seluruh jumlah populasi.

Variabel tergantung (dependent) dalam penelitian ini adalah status gizi bayi usia 4-6 bulan, sedangkan sebagai variabel bebas (independent) adalah pemberian makanan tambahan dini.

Penelitian ini menggunakan instrumen kuisioner dan timbangan Baby Scale merk GEA dengan ketelitian $0,1 \mathrm{~kg}$. Kuisioner diberikan pada ibu yang mempunyai bayi usia 4-6 bulan di daerah penelitian, sedangkan timbangan digunakan untuk mengukur berat badan bayi (dengan syarat bayi mengenakan pakaian seminimal mungkin) yang selanjutnya akan dibandingkan dengan usia bayi untuk mengetahui status gizi bayi.

\section{HASIL}

Hasil penelitian diperoleh berdasarkan hasil wawancara terhadap 126 ibu yang memiliki bayi berusia 4-6 bulan yang bertempat tinggal di Kecamatan Padang Barat, Kecamatan Padang Utara, dan Kecamatan Koto Tangah, Kota Padang, serta penimbangan berat badan bayi dari sampel yang bersangkutan.

Tabel 1a. Distribusi ibu berdasarkan umur, pendidikan terakhir dan pekerjaan ibu

\begin{tabular}{|c|c|c|}
\hline Karakteristik & Frekuensi & Persentase (\%) \\
\hline \multicolumn{3}{|l|}{ Umur Ibu } \\
\hline - $16-18$ tahun & 1 & 0,8 \\
\hline - $\quad 19-29$ tahun & 48 & 38,1 \\
\hline - $30-49$ tahun & 77 & 61,1 \\
\hline \multicolumn{3}{|l|}{ Jumlah } \\
\hline $\begin{array}{c}\bar{x}: 30,61 \text { tahun }(\text { SD }= \\
\pm 4,915)\end{array}$ & 126 & 100 \\
\hline
\end{tabular}

Tabel 1b. Distribusi pendidikan pekerjaan

\begin{tabular}{|c|c|c|}
\hline \multicolumn{3}{|c|}{ Pendidikan Terakhir } \\
\hline \multicolumn{3}{|l|}{ Ibu } \\
\hline - SD / Sederajat & 14 & 11,1 \\
\hline - SMP / Sederajat & 46 & 36,5 \\
\hline - SMA / Sederajat & 59 & 46,8 \\
\hline - Akademi / PT & 7 & 5,6 \\
\hline Jumlah & 126 & $100 \%$ \\
\hline \multicolumn{3}{|l|}{ Pekerjaan Ibu } \\
\hline - PNS & 1 & 0,8 \\
\hline - Pegawai Swasta & 1 & 0,8 \\
\hline - IRT & 120 & 95,2 \\
\hline - DII & 4 & 3,2 \\
\hline Jumlah & 126 & $100 \%$ \\
\hline
\end{tabular}

Berdasarkan Tabel 1 didapatkan bahwa sebagian besar responden ibu berusia 30 - 49 tahun, dengan rata-rata usia adalah 30,61 tahun. Selain itu, sebagian besar responden ibu berpendidikan > 12 tahun, yaitu tamat SMA / Sederajat dan bekerja sebagai lbu Rumah Tangga (IRT).

Tabel 2. Distribusi bayi berdasarkan jenis kelamin, usia, berat lahir bayi, dan pemberian ASI

\begin{tabular}{|c|c|c|}
\hline Karakteristik & Frekuensi & Persentase (\%) \\
\hline \multicolumn{3}{|l|}{ Jenis Kelamin Bayi } \\
\hline \multicolumn{3}{|l|}{ - Laki-Laki } \\
\hline \multirow[t]{2}{*}{ - Perempuan } & 60 & 47,6 \\
\hline & 66 & 52,4 \\
\hline Jumlah & 126 & 100 \\
\hline \multicolumn{3}{|l|}{ Usia Bayi } \\
\hline - 4 Bulan & 29 & 23,0 \\
\hline - 5 Bulan & 48 & 38,1 \\
\hline-6 Bulan & 49 & 38,9 \\
\hline Jumlah & 126 & 100 \\
\hline \multirow{2}{*}{\multicolumn{3}{|c|}{$\begin{array}{l}\bar{x}=5,16 \text { bulan } \\
(S D= \pm 0,774)\end{array}$}} \\
\hline & & \\
\hline \multicolumn{3}{|l|}{ Berat Lahir Bayi } \\
\hline - Normal & 121 & 96,0 \\
\hline - BBLR & 5 & 4,0 \\
\hline Jumlah & 126 & 100 \\
\hline \multicolumn{3}{|l|}{ Pemberian ASI } \\
\hline - Masih Diberi & 125 & 99,2 \\
\hline - Tidak Diberi & 1 & 0,8 \\
\hline Jumlah & 126 & 100 \\
\hline
\end{tabular}

Berdasarkan Tabel 2, terlihat bahwa sebagian besar responden bayi di daerah penelitian adalah perempuan, dengan rata-rata usia 5,16 bulan. Selain 
itu dari data di atas terlihat bahwa sebagian besar bayi lahir dengan berat badan normal ( $\geq 2500 \mathrm{gr}$ ) dan bayi masih diberi ASI.

Tabel 3. Distribusi bayi berdasarkan status gizi BB/U

\begin{tabular}{ccc}
\hline Status Gizi & Frekuensi & Persentase (\%) \\
& & \\
\hline Gizi Baik & 102 & 81.0 \\
Gizi Kurang & 24 & 19.0 \\
\hline Jumlah & $\mathbf{1 2 6}$ & $\mathbf{1 0 0}$ \\
\hline
\end{tabular}

Berdasarkan Tabel 3 terlihat bahwa sebagian besar bayi mempunyai status gizi yang baik.

Tabel 4. Distribusi bayi berdasarkan pemberian makanan tambahan dini

\begin{tabular}{ccc}
\hline PMT Dini & Frekuensi & Persentase (\%) \\
\hline Diberi & 101 & 80.2 \\
Tidak Diberi & 25 & 19.8 \\
\hline Jumlah & $\mathbf{1 2 6}$ & $\mathbf{1 0 0}$ \\
\hline
\end{tabular}

Berdasarkan Tabel 4 didapatkan bahwa sebagian besar bayi telah diberi makanan tambahan sebelum usia 6 bulan.

Tabel 5. Distribusi bayi berdasarkan keluhan setelah pemberian makanan tambahan dini selama 2 minggu terakhir

\begin{tabular}{lcc}
\hline \multicolumn{1}{c}{ Keluhan } & Frekuensi & $\begin{array}{c}\text { Persentase } \\
\text { (\%) }\end{array}$ \\
\hline Tidak Sakit & 41 & 40,6 \\
Sakit & 60 & 59,4 \\
- Demam & 32 & 31,7 \\
- Demam, Diare & 8 & 7,9 \\
- Batuk, Flu & 12 & 11,9 \\
- DIl & 8 & 7,9 \\
\hline \multicolumn{1}{c}{ Jumlah } & $\mathbf{1 0 1}$ & $\mathbf{1 0 0}$ \\
\hline
\end{tabular}

Berdasarkan Tabel 5 terlihat bahwa sebagian besar bayi yang telah diberi makanan tambahan dini menderita sakit dalam 2 minggu terakhir. Gejala yang paling banyak ditemui adalah demam.
Tabel 6. Hubungan pemberian makanan tambahan dini dengan status gizi bayi

\begin{tabular}{|c|c|c|c|c|c|c|c|}
\hline \multirow{3}{*}{$\begin{array}{l}\text { PMT } \\
\text { Dini }\end{array}$} & \multicolumn{5}{|c|}{ Status Gizi } & \multirow{2}{*}{\multicolumn{2}{|c|}{ p }} \\
\hline & \multicolumn{2}{|c|}{ Baik } & \multicolumn{3}{|c|}{ Kurang } & & \\
\hline & $F$ & $\%$ & $F$ & $\%$ & $F$ & $\%$ & \\
\hline $\begin{array}{l}\text { Tidak } \\
\text { Diberi }\end{array}$ & 24 & 96,0 & 1 & 4,0 & 25 & 100 & \\
\hline & & & & & & & 0,043 \\
\hline Diberi & 78 & 77,2 & 23 & 22,8 & 101 & 100 & \\
\hline
\end{tabular}

Fisher's Exact Test $=0,043$

Berdasarkan Tabel 6, didapatkan bahwa persentase bayi dengan status gizi kurang lebih banyak pada bayi yang telah diberi makanan tambahan dini, yakni sebanyak 23 orang.

\section{PEMBAHASAN}

Berdasarkan hasil tabulasi silang (crosstabs) pada Tabel 6 antara pemberian makanan tambahan dini dengan status gizi bayi usia 4-6 bulan, sebagian besar bayi yang telah diberi makanan tambahan mempunyai status gizi kurang. Data uji statistik dengan menggunakan Fisher's Exact Test pun menunjukkan nilai $p 0,043$ ( $p$ value $<0,05$ ). Hal ini menunjukkan bahwa adanya hubungan yang bermakna antara pemberian makanan tambahan dini dengan status gizi bayi usia 4-6 bulan.

Pemberian makanan tambahan mutlak bagi bayi jika diberikan pada usia yang tepat agar bayi dapat tumbuh dan berkembang secara optimal. Namun bila bayi diberikan makanan tambahan pada usia yang belum genap 6 bulan, maka dapat terjadi penyakit infeksi dan penyakit kronis. ${ }^{10}$ Pada penelitian ini sebanyak $59,4 \%$ bayi menderita sakit selama 2 minggu terakhir setelah pemberian makanan tambahan. Jenis penyakit yang sering diidap seperti demam $(31,7 \%)$ dan batuk flu (11,9\%). Hal ini menunjukkan bahwa bayi lebih rentan terkena infeksi setelah pemberian makanan tambahan dini. 
Berdasarkan penelitian yang dilakukan oleh WHO tahun 1989-1992 di beberapa negara di dunia, didapatkan bahwa tubuh bayi dengan ASI eksklusif atau predominan ASI mempunyai daya proteksi terhadap infeksi yang lebih tinggi dibanding dengan bayi yang diberi makanan tambahan dini.

Penelitian lain dilakukan oleh Khadivzadeh dan Parsai pada tahun 2004 di Provinsi Khorasan Razavi, Iran. Dari penelitian tersebut didapatkan bahwa persentase kejadian diare lebih rendah pada bayi yang diberi ASI eksklusif dibanding dengan bayi yang diberi makanan tambahan (11:27). Perbedaan persentase juga terjadi pada kejadian infeksi saluran pernafasan. Persentase infeksi saluran pernafasan pada bayi yang diberi ASI eksklusif lebih rendah dibanding dengan bayi yang diberi makanan tambahan, yakni $23: 35 .{ }^{11}$

Hasil yang sama juga didapat dari penelitian yang dilakukan oleh Murniningsih dan Sulastri tahun 2007, pemberian makanan tambahan pada bayi usia di bawah 6 bulan dapat menurunkan tingkat kesehatan dan mengakibatkan gangguan kesehatan di kemudian hari. Bayi dapat terkena diare karena proses penyiapan makanan yang kurang higienis. Selain itu, alergi juga dapat terjadi karena sel-sel di sekitar usus belum siap untuk menerima kandungan dari makanan, sehingga makanan yang masuk menyebabkan timbulnya reaksi imun dan alergi, seperti batuk, flu, ronkhi, dan dermatitis. ${ }^{8}$

\section{KESIMPULAN}

Angka pemberian makanan tambahan dini pada bayi usia 4-6 bulan di daerah Padang Barat, Padang Utara, dan Koto Tangah masih sangat tinggi yaitu $80,2 \%$ dan angka status gizi kurang pada bayi usia 4-6 bulan pun masih tinggi yaitu 19\%. Selain itu, data penelitian menunjukkan adanya hubungan antara pemberian makanan tambahan dini terhadap status gizi bayi usia 4-6 bulan di kecamatan Padang Barat, Padang Utara, dan Koto Tangah, kota Padang.

\section{UCAPAN TERIMA KASIH}

Terima kasih kepada Dinas Kesehatan Kota
Padang dan Fakultas Kedokteran Universitas Andalas atas izin dan fasilitas yang telah diberikan demi kelancaran penelitian ini.

\section{DAFTAR PUSTAKA}

1. Ikatan Dokter Anak Indonesia. Buku ajar I tumbuh kembang anak dan remaja. Jakarta: CV. Sagung Seto; 2008.

2. Anwar F, Riyadi H. Status gizi dan status kesehatan suku baduy. Jurnal Gizi dan Pangan. 2009;4(2):72-82.

3. Kemenkes RI. Riset kesehatan dasar (Riskesdas). Badan Penelitian dan Pengembangan Kesehatan Kementerian Kesehatan RI; 2010.

4. Dinkes kota Padang. Profil kesehatan kota Padang. Bidang Pelayanan Kesehatan Dinas Kesehatan kota Padang; 2012.

5. Proverawati A, Rahmawati E. Kapita selekta ASI \& menyusui. Yogyakarta: Nuha Medika; 2010.

6. Ikatan Dokter Anak Indonesia. Bedah ASI. Jakarta: Balai Penerbit FKUI; 2008.

7. World Health Organization (WHO). Indonesia Global Health Observatory Data. WHO Global Data Bank on Infant and Young Child Feeding (IYCF); 2008.

8. Murniningsih, Sulastri. Hubungan antara pemberian makanan tambahan pada usia dini dengan tingkat kunjungan ke pelayanan kesehatan di kelurahan sine sragen. Berita IImu Keperawatan Sragen. 2008;1:113-8.

9. Michaelsen KF, Weaver L, Branca F, Robertson A. Feeding and nutrition of infants and young children: Guideline for the WHO european region, with emphasis on the former soviet countries. Denmark: WHO Regional Office for Europe; 2003.

10. Clark SGJ, Bungum TJ. The benefits of breastfeeding: an introduction for health education. Californian Journal of Health Promotion Las Vegas. 2003;1:158-63.

11. Khadivzadeh T, Parsai S. Effect of exclusive breastfeeding and complementary feeding on infant growth and morbidity. Eastern Mediterranean Health Journal Iran. 2004;10:289-94. 